\title{
Analysis of Marine Industry Structure and Competitiveness in Zhejiang Province Based on the Shift-share Method
}

\author{
XU Jianjun \\ ${ }^{1}$ Institute of Science and Technology Ningbo University, Ningbo 315211, PR. China \\ xu-jj@hotmail.com
}

Keywords: Marine industry structure; Marine industry competitiveness; Shifted-share method

\begin{abstract}
Based on marine statistical data from 2001 to 2012, this paper analyzes the marine industry structure and competitiveness of Zhejiang with the Shifted-share method. According to horizontal static comparison, the results show that the marine industry growth of Zhejiang is resulted from the growth of the national marine industries, which ranks after Jiangsu and Shandong. After longitudinal dynamic investigation, the results show that the growth rate of marine industry of Zhejiang is unstable, sometimes it is higher than the growth rate of national marine industry while sometimes its lower than the latter; the growth effect brought by the structure component and competitiveness component of marine industry shows no apparent fluctuation rules and that the positive growth effect brought by both is lightly more than the negative growth effect.
\end{abstract}

\section{Introduction}

Located in the south of the Yangtze River Delta on the East China Sea, with a coastline of 6486km and a sea area of about 260,000 square kilometers, Zhejiang Province enjoys rich marine resources. Since the 21st Century, under the guidance of the marine national development strategy, marine resources of Zhejiang have been further developed and utilized, marine economy has been developed more rapidly, and the proportion of tertiary marine industries has been becoming more reasonable. On February 25th, 2011, the State Council of China officially approved the "Planning of Marine Economic Development Demonstration Area of Zhejiang Province", which clearly put forward the goal of Zhejiang, which is to take speeding up the transformation of economic development as the main line, to focus on optimizing the structure of marine economy, and to construct a marine economic development demonstration area with outstanding core competitiveness, reasonable space allocation, good ecological environment and a flexible institutional mechanisms. Under this background, this paper gives a reasonable evaluation of Zhejiang marine industry structure and its competitiveness based on the shift-share method (SSM), which will provide empirical evidence for the related policy adjustment.

The basic idea of SSM decomposed the economic variables of a specific region, such as income, output and employment, into different growth parts, so as to evaluate the reason of regional economic growth, the evaluation of the regional economic structure and its competitive strength (Shi Chunyun et al. 2007 ${ }^{[1]}$. Since the SSM was applied to study the geographical distribution of the industrial population of English (particularly in the southeastern region) by Jones (1940) ${ }^{[2]}$, the SSM had been widely applied in city planning, geography and regional sciences (Ledebur and Moomaw, 1983 ${ }^{[3]}$; Knudsen, $2000^{[4]}$ ). In recent years, the SSM has been used for the analysis of China's marine industry structure. $\mathrm{Li}$, et al (2010) ${ }^{[5]}$ utilized static SSM to study the overall competitiveness of three marine industries in China during 2006-2008. Zhai and Li (2011) ${ }^{[6]}$ used the SSM to study spatio-temporal difference of China's marine industry structure. Tang (2011) ${ }^{[7]}$ made use of the SSM to comparatively analyze the marine industry structure of two sessions (2001-2005, 2005-2009) of Jiangsu.

There is no doubt that the above literature has played a guiding role in the further analysis of marine industrial structure. However, the above literature only used the static SSM to analyze the marine industry structure, which only concerned the whole change from the base period to the reporting period, 
but did not take into account the continuous process change of the decomposition variables. Therefore, it is necessary to introduce the dynamic SSM into the analysis of marine industry structure and competitiveness.

\section{The Principles of the Shifted-share Method}

According to reference [8-10], assuming that the total amount and the structure of marine industry in region $\mathrm{j}$ has changed from base period $\mathrm{t}_{0}$ to report period $\mathrm{t}_{1}$. According to "The Classification of Marine and Related Industries" (GB/T20794-2006), the marine economy in region $\mathrm{j}$ is divided into $\mathrm{i}$ $(\mathrm{i}=1,2,3)$ industries, $g_{i j}\left(t_{0}\right)$ represents the ith marine industry output of region $\mathrm{j}$ in the base period $\mathrm{t}_{0}, g_{i j}\left(t_{1}\right)$ represents the ith marine industry output of region $\mathrm{j}$ in the report period $\mathrm{t}_{1}, g\left(t_{0}\right)$ represents the ith national marine industrial output in the base period $t_{0}, g\left(t_{1}\right)$ represents the ith national marine industrial output in the report period $\mathrm{t}_{1}$, then the growth $\Delta g_{i j}$ of the ith marine industrial output of region $\mathrm{j}$ from base period $\mathrm{t}_{0}$ to report period $\mathrm{t}_{1}$ can be expressed as:

$$
\begin{aligned}
\Delta g_{i j}\left(t_{1}\right) & =g_{i j}\left(t_{0}\right)\left[\frac{g\left(t_{1}\right)}{g\left(t_{0}\right)}-1\right]+g_{i j}\left(t_{0}\right)\left[\frac{g_{i}\left(t_{1}\right)}{g_{i}\left(t_{0}\right)}-\frac{g\left(t_{1}\right)}{g\left(t_{0}\right)}\right]+g_{i j}\left(t_{0}\right)\left[\frac{g_{i j}\left(t_{1}\right)}{g_{i j}\left(t_{0}\right)}-\frac{g_{i}\left(t_{1}\right)}{g_{i}\left(t_{0}\right)}\right] \\
G_{i} & =N_{i}+P_{i}+D_{i}
\end{aligned}
$$

The formula(1) consists of three parts, the first item $N_{i}$ is the expected value of the ith marine industrial growth amount in region $\mathrm{j}$, which represents the growth along with national marine industrial growth amount from $\mathrm{t}_{0}$ to $\mathrm{t}_{1}$; the second item $P_{i}$ is the industrial structure component of the ith marine growth amount of region $\mathrm{j}$, which represents the amount of change of the ith marine industry in region $\mathrm{j}$ taking the ith national marine industrial growth as the evaluation criterion; the third item $D_{i}$ is the competitiveness of the ith marine industry in region $j$, which represents the quality of the ith marine industry in region $\mathrm{j}$ compared to the ith national marine industry.

When focusing on the definition of $t_{0}=2001$ and $t_{1}=2012$, formula (1) is also the so-called static SSM model; however, if the study period from 2001 to 2012 is divided into 12 periods, the decomposing result of the marine industry growth reflects the dynamic change of marine industry structure and competitiveness component in the different period, and then the formula (1) becomes the dynamic SSM model.

The basic data in Zhejiang during 2001-2012 and the other 10 coastal provinces of the marine industry GDP come from the "China Marine Statistical Yearbook" (2002-2013).

\section{The horizontal comparison of Zhejiang marine industry structure and competitiveness}

Figure 1 shows the decomposition result of the marine industry in Zhejiang and other 10 provinces according to the formula (1). According to Figure 1, the absolute growth in Zhejiang ranks after Guangdong, Shandong, Shanghai and Jiangsu. The actual growth amount $\Delta g$ of Zhejiang, Fujian, Guangdong, Guangxi and Hainan is less than the corresponding province $N_{i}$, which indicates that the marine industry growth of these 5 provinces is driven by the national marine industry growth. The growth changes of other six provincial marine industries are higher than the national average. In view of the industrial component, the share component of the marine industry structure $N_{i}$ of Hebei, Tianjin, Shanghai, Guangdong is positive, while the other components of the marine industry structure in other 7 provinces including Zhejiang is negative, which indicates that only Hebei, Tianjin, Guangdong and Shanghai have the comparative advantage of marine industry structure, while the marine industry structure in other 7 provinces including Zhejiang have disadvantages. From the view of competitiveness component, the competitiveness component of marine industry in 8 provinces including Zhejiang is positive, suggesting that the marine industry competitiveness in these provinces is stronger. Among them, the competitiveness of Zhejiang ranks after Jiangsu and Shandong. 

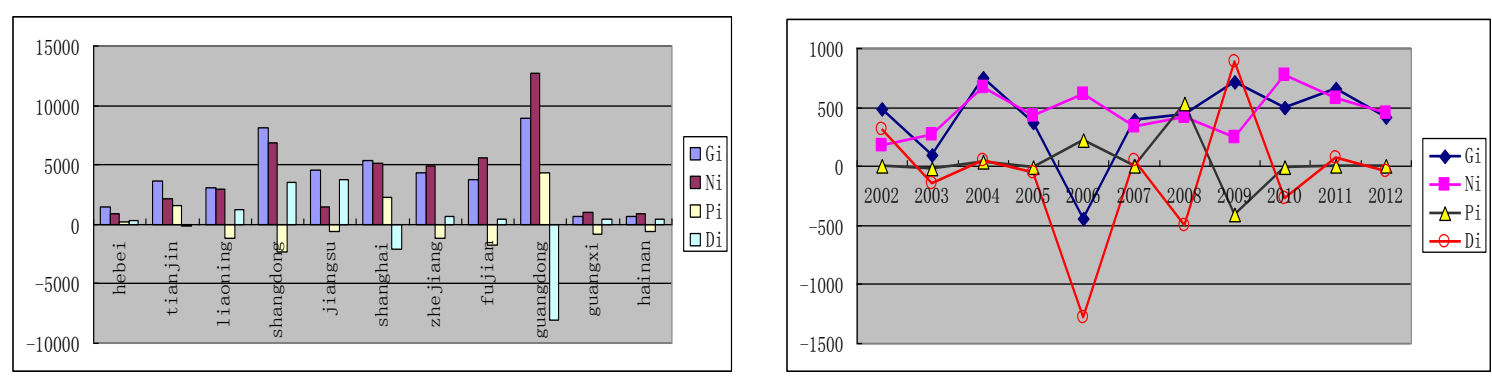

Figure 1 Static Decomposition of Marine Industry Figure 2 Dynamic Decomposition of Marine Industry

Table 1 indicates the decomposition results of the marine industry in 11 coastal provinces during 2001-2012 according to the formula (1). Firstly, the author analyzes the decomposition of primary marine industry. From the national component perspective, the Ni of 11 coastal provinces, including Zhejiang is greater than the corresponding provincial marine primary industry growth volume. From structure component of the marine primary industry, the Pi of 11 provinces including Zhejiang is negative. From a point of competitiveness components of marine primary industry, the Di of Hebei, Liaoning, Jiangsu, Zhejiang, Guangxi and Hainan is positive. However, after further comparing the results of decomposition, it is found that the Di of Zhejiang is only 3.031 billion Yuan, ranking after Liaoning (17.765 billion Yuan) and Hainan (4.658 billion Yuan), indicating that there is a gap between Zhejiang and those provinces with strong competitiveness.

Table 1 The SSM Static Decomposition of Marine Industry in Different Provinces

\begin{tabular}{|l|c|c|c|c|c|c|c|c|c|c|c|c|}
\hline \multirow{2}{*}{ Region } & \multicolumn{4}{|c|}{ Marine Primary Industry } & \multicolumn{3}{c|}{ Marine Secondary Industry } & \multicolumn{4}{c|}{ Marine Tertiary Industry } \\
\cline { 2 - 14 } & $\mathrm{Gi}$ & $\mathrm{Ni}$ & $\mathrm{Pi}$ & $\mathrm{Di}$ & $\mathrm{Gi}$ & $\mathrm{Ni}$ & $\mathrm{Pi}$ & $\mathrm{Di}$ & $\mathrm{Gi}$ & $\mathrm{Ni}$ & $\mathrm{Pi}$ & $\mathrm{Di}$ \\
\hline Hebei & 29.21 & 342.2 & -334.5 & 21.56 & 644.4 & 359.3 & 424.8 & 48.49 & 1506 & 248.6 & 94.8 & 301 \\
\hline Tianjin & 0.87 & 57.7 & -56.41 & -0.42 & 2501 & 1024 & 1211 & 265.9 & 1168 & 1123 & 428.2 & -382.8 \\
\hline Liaoning & 201.2 & 2017 & -1972 & 156.1 & 1272 & 552.1 & 652.9 & 67.44 & 1556 & 404.6 & 154.3 & 996.9 \\
\hline Shangdong & 94.18 & 4551 & -4450 & -7.56 & 4178 & 1518 & 1795 & 865.5 & 3859 & 831.6 & 317.1 & 2711 \\
\hline Jiangsu & 95.25 & 1027 & -1004 & 72.29 & 2401 & 313.3 & 370.4 & 1717 & 2055 & 71.08 & 27.1 & 1957 \\
\hline Shanghai & -10.24 & 118.5 & -115.9 & -12.89 & 2171 & 632.1 & 747.4 & 791.7 & 3160 & 4379 & 1670 & -2888 \\
\hline Zhejiang & 66.45 & 2489 & -2433 & 10.81 & 2135 & 374 & 442.3 & 1319 & 2146 & 2065 & 787.5 & -706.9 \\
\hline Fujian & 39.24 & 3095 & -3026 & -29.94 & 2205 & 378.1 & 447 & 1380 & 1990 & 2142 & 816.7 & -968.9 \\
\hline Guangdong & -222 & 3300 & -3227 & -295.8 & 4524 & 5013 & 5928 & -6416 & 4662 & 4349 & 1658 & -1345 \\
\hline Guangxi & 58.02 & 859.2 & -840 & 38.81 & 144.4 & 1.64 & 1.94 & 140.8 & 429.3 & 133.5 & 50.89 & 245 \\
\hline Hainan & 61.87 & 663.4 & -648.6 & 47.04 & 299.4 & 19.86 & 23.49 & 256 & 297.4 & 156.4 & 59.65 & 81.35 \\
\hline
\end{tabular}

Then, the author investigates the decomposition of secondary marine industry. From the perspective of national component $\mathrm{Ni}$, besides Guangdong, the actual growth of the secondary marine industry of the remained 10 provinces including Zhejiang is higher than the share of national component. From the point of structural component $\mathrm{Pi}$, the structure components of the marine secondary industry in 11 provinces are positive, indicating that the secondary marine industry structure has brought positive growth effect. From the view of competitiveness component Di, only the competitiveness component of Guangdong is negative, including Zhejiang, there are 10 provinces' marine secondary industrial competitiveness component is positive. Among them, Zhejiang's competitiveness component of marine secondary industry is 122.586 billion Yuan, ranking after Jiangsu (162.998 billion Yuan).

Finally, the author analyzes the decomposition results of the marine tertiary industry. From the view of national component $\mathrm{Ni}$, in addition to the real growth of marine tertiary industry in Shanghai and Fujian is less than the national level, the other 9 provinces' actual growth of the marine tertiary industry, is greater than the national share. From the view of structure component of the marine industry, the structure components of marine tertiary industry of 11 provinces, including Zhejiang, are all positive. From the view of competitiveness component, the Di value of marine tertiary industry in 
Hebei, Liaoning, Shandong, Jiangsu, Guangxi and Hainan are all positive. And the marine tertiary industry competitiveness of Tianjin, Shanghai, Zhejiang, Fujian and Guangdong is negative.

\section{A longitudinal investigation of Zhejiang marine industry structure and competitiveness}

Figure 2 shows the dynamic decomposition of marine industry structure in Zhejiang. From Figure 2, the actual growth of the marine industry $\Delta g$ during 2002, 2004, 2007, 2008, 2009 and 2011 is larger than the national average level, which means that the level of marine industry's growth in Zhejiang of the corresponding years is higher than the general level of the whole country. In 2003, 2005, 2010 and 2012, the actual growth of the marine industry $\Delta g$ is lower than the national average level, which means that the increase of Zhejiang' marine industry during these years results from national growth. From the component of industrial structure, component of marine industrial structure $P_{i}$ in 2004, 2006, 2007, 2008, 2011 and 2012 is positive, indicating that the marine industry structure in Zhejiang has brought positive growth effect on these 6 years, but another 5 years have the negative growth effect. From the view of competitiveness component, competitiveness of marine industry $D_{i}$ is positive in 2002, 2004, 2007, 2009 and 2011, indicating that a competitiveness of the Zhejiang marine industry brings positive growth effect only in these 5 years.

Table 2 shows the dynamic decomposition result of the marine industry structure in Zhejiang based on Formula (1). Table 2 indicates that the national component of marine primary industry is larger than the real growth in volume of marine primary industry during 2002-2010, while the national component of marine primary industry is lower than the real growth volume of marine primary industry in Zhejiang during 2011-2012. From the point of structural component Pi, marine primary industrial structure component in Zhejiang only in 2003, 2007, 2009, 2010 and 2011, is positive, while in other year, Pi shows a negative growth effect. From the competition component Di, Zhejiang's marine primary industrial competitiveness component is positive only in 2002, 2004, 2008, 2010 and 2011, while a competitiveness component of Zhejiang in other year is negative.

Table 2 The SSM Dynamic Decomposition of Marine Industry in Zhejiang

\begin{tabular}{|c|c|c|c|c|c|c|c|c|c|c|c|c|}
\hline & \multicolumn{4}{|c|}{ Marine Primary Industry } & \multicolumn{3}{c|}{ Marine Secondary Industry } & \multicolumn{3}{c|}{ Marine Tertiary Industry } \\
\cline { 2 - 13 } & $\mathrm{Gi}$ & $\mathrm{Ni}$ & $\mathrm{Pi}$ & $\mathrm{Di}$ & $\mathrm{Gi}$ & $\mathrm{Ni}$ & $\mathrm{Pi}$ & $\mathrm{Di}$ & $\mathrm{Gi}$ & $\mathrm{Ni}$ & $\mathrm{Pi}$ & $\mathrm{Di}$ \\
\hline 2002 & 79.1 & 88.1 & -49.9 & 40.9 & 121.2 & 13.2 & 0.5 & 107.5 & 281.9 & 73.1 & 46.3 & 162.5 \\
\hline 2003 & 18.7 & 93.7 & 11.5 & -86.5 & 121.0 & 40.9 & 20.2 & 59.9 & -44.6 & 130.8 & -50.7 & -124.7 \\
\hline 2004 & 200.2 & 228.3 & -138.3 & 110.1 & 276.9 & 163.8 & -41.9 & 155.0 & 271.1 & 278.3 & 214.0 & -221.1 \\
\hline 2005 & 46.8 & 133.8 & -41.4 & -45.7 & 172.6 & 125.7 & 17.8 & 29.1 & 153.5 & 169.2 & 20.1 & -35.7 \\
\hline 2006 & -510.2 & 172.7 & -658.9 & -24.0 & -1.1 & 196.5 & 900.2 & -1098.0 & 69.0 & 243.5 & -17.4 & -157.0 \\
\hline 2007 & 16.2 & 24.9 & 3.5 & -12.1 & 173.5 & 132.8 & -17.5 & 58.2 & 198.2 & 177.3 & 19.6 & 1.3 \\
\hline 2008 & 78.0 & 28.2 & -2.4 & 52.2 & 214.3 & 166.4 & 46.8 & 1.0 & 140.3 & 216.1 & 482.3 & -558.0 \\
\hline 2009 & 6.3 & 20.7 & 15.3 & -29.7 & 435.0 & 100.4 & -21.3 & 355.9 & 274.2 & 118.0 & -399.9 & 556.1 \\
\hline 2010 & 48.4 & 53.9 & -34.6 & 29.1 & 204.4 & 352.3 & 59.2 & -207.1 & 238.3 & 360.6 & -30.9 & -91.3 \\
\hline 2011 & 63.7 & 42.9 & 10.5 & 10.3 & 258.9 & 263.9 & -7.8 & 2.8 & 330.6 & 274.5 & 1.0 & 55.1 \\
\hline 2012 & 35.0 & 7.4 & -23.2 & -15.7 & 202.2 & -35.8 & -8.2 & -44.0 & 216.4 & 33.7 & -16.9 & 16.8 \\
\hline
\end{tabular}

Likewise, the real growth of Zhejiang's marine secondary industry in 2006, 2010 and 2011 is less than the national component, while the actual growth of marine secondary industry in Zhejiang during the rest years is higher than the national share component. From the structural component Pi, Zhejiang marine industrial structure component is positive in 2002, 2003, 2005, 2006, 2008 and 2010, and there is only a negative growth effect in the rest years. From the competitiveness component, Pi of Zhejiang in 2006, 2010 and 2012 is negative, and the rest of the years are positive. Similarly, the actual growth of marine tertiary industry is less than national component in 2003, 2004, 2005, 2006, 2008 and 2010, while the actual growth of marine tertiary industry is larger than the national component in the rest year. From the view of structure component Pi, except for 2003, 2006, 2009, 2010, 2012 years, Pi of Zhejiang bring the negative growth effect in the rest year. From the competitiveness component Di, the 
competitiveness component of marine tertiary industry in 2002, 2007, 2009, 2011 and 2012 are positive, while Di brought about negative growth effect in the rest years.

\section{Conclusions}

Based on the data during 2001-2012, this paper uses the SSM to analyze the dynamic and static marine industry structure and competitiveness of Zhejiang and obtained the following conclusions:

(1)The marine industry growth of Zhejiang, Fujian, Guangdong, Guangxi and Hainan results from national marine industry growth. The marine industry structure in the remaining 7 provinces including Zhejiang is at a disadvantage state. However, the marine industry competitiveness of the 8 provinces including Zhejiang is relatively strong. Among them, marine competitiveness of Zhejiang ranks after Jiangsu and Shandong. (2) The decomposition of tertiary marine industry shows that the growth of the primary marine industry of the 11 coastal provinces is brought by national marine growth, while its growth rate of the secondary and tertiary industries are higher than the national average level. (3) Compared to the growth rate of national marine industry, the marine industry growth of Zhejiang is unstable, sometimes it is higher than the growth of national marine industries while sometimes it's lower than the latter; and the positive growth effect brought by structure and competitiveness component of marine industry is slightly higher than the negative effects. (4) Dynamic decomposition of marine tertiary industry shows different patterns. Among them, marine growth of primary industry in Zhejiang during 2002-2010 is brought by the national marine primary industry growth; the positive growth effect brought by structure change in the marine secondary and tertiary industry of Zhejiang only last for half of the inspection period; the growth effect of competitiveness of marine secondary and tertiary industry accounts for 8/11 and 5/11 year respectively.

\section{Acknowledgement}

This work was financially supported by Soft Science Research Program of the Department of Science and Technology in Zhejiang Province (No.2013C35025)

\section{References}

[1] Shi C.Y, Zhang J, Gao W. Review of shift share analysis and the development model abroad [J]. Inquiry into Economy Issue, 2007 (3): 133-136.

[2] Jones, J.H. A memorandum of the location of industry, the royal commission on the distribution of industrial population (Barlow Report) [M]. London: HMSO Command 6153, 1940.

[3] Ledebur, L C., and B. L Moomaw. A shift-share analysis of regional labor productivity in manufacturing [J]. Growth and Change, 1983 (1): 2-9.

[4] Knudsen D C. Shift-share analysis further examination of models for the description of economic change[J]. Socio-economic Planning Sciences, 2000, 34(3):177-198.

[5] Li B, Gao Y, and Zhang S.Y. The comparison of the regional marine industry competitiveness based on Shift Share Method[C].The Fifth Management Cademic Year in China, 2010.

[6] Zhai R.X, Li M. R. On Spatio-temporal difference of China's marine industry structure : based on shift-share method [J]. Mathematics in Practice and Theory, 2011 (10): 44-51.

[7] Tang Z. K. The analysis of marine industrial structure based on shift share model -- take Jiangsu for example [J]. Technology Economic and Management Research, 2011 (12): 97-100.

[8] Hellm. A Shift-share model as the Predictive Tool [J].Growth and Change, 1976(7): 3-8.

[9] Barff R A and Prentice L K. Dynanic shift-share anaysis [J]. Growth and Chang, 1988(3):1-11. 
[10]Esteban-Marquillas J M. A reinterpretation of shift-share analysis[J]. Regional and Urban Economics, 1972, 2(3):249-255. 